OLIVEIRA, FA; OLIVEIRA, JM; SOUZA NETA, ML; OLIVEIRA, MKT; ALVES, RC. 2017. Substrato e bioestimulante na produção de mudas de maxixeiro. Horticultura Brasileira 35: 141-146. DOI - http://dx.doi.org/10.1590/S0102-053620170122

\title{
Substrato e bioestimulante na produção de mudas de maxixeiro
}

\author{
Francisco A Oliveira' ${ }^{1}$ Jaira M Oliveira ${ }^{1}$; Maria L Souza Neta ${ }^{1}$; Mychelle KT Oliveira ${ }^{1}$; Rita C Alves ${ }^{2}$ \\ ${ }^{1}$ Universidade Federal Rural do Semiárido (UFERSA), Mossoró-RN, Brasil; thikaoamigao@ufersa.edu.br; jairariany@hotmail.com; lilia. \\ agronomia@hotmail.com; mymykar@gmail.com; ${ }^{2}$ Universidade Estadual Paulista (UNESP), Jaboticabal-SP, Brasil; cassiaagro-24@ \\ outlook.com
}

\section{RESUMO}

O maxixeiro (Cucumis anguria) é uma hortaliça-fruto da família Cucurbitaceae, de grande importância para a culinária das regiões Norte e Nordeste do Brasil; entretanto, ainda é uma cultura pouco estudada, inclusive na etapa de produção de mudas. $\mathrm{O}$ experimento foi desenvolvido com o objetivo de avaliar o efeito do tratamento de sementes com bioestimulante e diferentes substratos na produção de mudas de maxixeiro. O delineamento experimental foi inteiramente casualizado, com os tratamentos distribuídos em esquema fatorial 2 (presença ou ausência do bioestimulante) x 9 (diferentes substratos formulado); os substratos foram formulados a partir de misturas de fibra de coco (FC) e Tropstrato HT hortaliças ${ }^{\circledR}$ (THT) [S1= $\mathrm{FC} ; \mathrm{S} 2=\mathrm{FC}+\mathrm{THT}(4: 1) ; \mathrm{S} 3=\mathrm{FC}+\mathrm{THT}(3: 1) ; \mathrm{S} 4=\mathrm{FC}+\mathrm{THT}(2: 1)$; $\mathrm{S} 5=\mathrm{FC}+\mathrm{THT}(1: 1) ; \mathrm{S} 6=\mathrm{FC}+\mathrm{THT}(1: 2) ; \mathrm{S} 7=\mathrm{FC}+\mathrm{THT}$ (1:3); S8= FC+THT (1:4); S9= THT]. Foram avaliados o número de folhas, altura de planta, diâmetro de colo, comprimento da raiz principal, massa seca da parte aérea, massa seca da raiz e massa seca total. Houve interação significativa entre os fatores estudados para a maioria das variáveis analisadas, demonstrando que a eficiência do bioestimulante está relacionada à condição de umidade e nutrientes proporcionada pelo substrato. Mudas com maior número de folhas $(4,9-5,2)$, altura $(11,46-14,53 \mathrm{~cm})$, comprimento de raíz principal $(9,32-10,21 \mathrm{~cm})$, massa seca de parte aérea $(0,78-0,92 \mathrm{~g})$, massa seca total $(1,09-1,12$ g) foram obtidas com tratamento de sementes com bioestimulante nos substratos S4, S5 e S6. O tratamento de sementes com bioestimulante Stimulate ${ }^{\circledR}$ proporcionou melhor desenvolvimento das plantas de maxixeiro Liso de Calcutá, principalmente com os substratos S4, S5 e S6. O uso dos substratos fibra de coco ou Tropstrato HT Hortaliças ${ }^{\circledR}$ isolados não é eficiente na produção de muda de maxixeiro.

Palavras-chave: Cucumis anguria, hormônios vegetais, fibra de coco.

\begin{abstract}
Substrate and biostimulant in the production of gherkin seedlings
\end{abstract}

Gherkin (Cucumis anguria) is a vegetable-fruit of the Cucurbitaceae family, of great importance to the cuisine of North and Northeast Brazil. However, gherkin is still a little studied crop, including the seedling production stage. The experiment was carried out to evaluate the effect of seed treatment with biostimulant and different substrates in the production of gherkin seedlings. The experimental design was completely randomized, with treatments distributed in factorial 2 (presence or absence of the biostimulant) $\mathrm{x}$ 9 (different formulated substrates); substrates were formulated from mixtures of coconut fiber (FC) and Tropstrato HT vegetables (THT) $[(\mathrm{S} 1=\mathrm{FC} ; \mathrm{S} 2=\mathrm{FC}+\mathrm{THT}(4: 1) ; \mathrm{S} 3=\mathrm{FC}+\mathrm{THT}(3: 1) ; \mathrm{S} 4=\mathrm{FC}+\mathrm{THT}$ (2:1); S5= FC+THT (1:1); S6= FC+THT (1:2); S7= FC+THT (1:3); $\mathrm{S} 8=\mathrm{FC}+\mathrm{THT}(1: 4) ; \mathrm{S} 9=\mathrm{THT}]$. We evaluated the number of leaves, plant height, stem diameter, main root length, shoot dry weight, root dry mass and total dry mass. A significant interaction between the factors studied was observed for most of the variables analyzed, showing that the biostimulant efficiency is related to the moisture condition and nutrients provided by the substrate. Seedlings with more leaves (4.9-5.2), height (11.46 - $14.53 \mathrm{~cm})$, main root length $(9.32-10.21 \mathrm{~cm})$, dry weight of the aboveground part $(0.78-0.92$ g), total dry weight (1.09 - $1.12 \mathrm{~g})$ were obtained by treating seeds with biostimulant in the substrates S4, S5 and S6. We concluded that the treatment of seeds with biostimulant Stimulate ${ }^{\circledR}$ enhanced growth of gherkin plants 'Liso de Calcuta', especially with the substrates S4, S5 and S6.

Keywords: Cucumis anguria, vegetal hormones, coconut fiber.

\section{(Recebido para publicação em 15 de setembro de 2015; aceito em 30 de agosto de 2016) (Received on September 15, 2015; accepted on August 30, 2016)}

$\mathrm{O}$ maxixe (Cucumis anguria) é uma hortaliça-fruto da família Cucurbitaceae, que foi trazida da África pelos escravos, disseminando-se pelas diferentes regiões do Brasil. Entretanto, é mais consumido nas regiões Norte, Nordeste e Centro-Oeste (Oliveira et al., 2010). Apesar de ser uma hortaliça importante para essas regiões, especialmente pela participação na culinária brasileira, ainda é considerada uma cultura subutilizada e/ou secundária, sendo ainda pouco estudada (Oliveira et al., 2014), inclusive na fase de produção de mudas (Cardoso et al., 2013).

Um fator chave para a obtenção de mudas de qualidade está na escolha do substrato, principalmente na escolha dos componentes utilizados na sua formulação, em relação à cultura utilizada. No caso de espécies pertencentes à família das Cucurbitaceas, deve-se dar atenção porque as mesmas não toleram a formação de raiz nua (Anjos et al., 2003), sendo necessário um substrato em que o sistema radicular forme um bloco de fácil desprendimento das bandejas para que não ocorram danos mecânicos.

Dentre os materiais utilizados no preparo de substratos, o mesocarpo de 
coco pode ser utilizado no estágio verde ou seco pois apresenta características desejáveis para um bom substrato, tais como alta retenção de umidade, resistência à degradação, uniformidade, ser livre de patógenos e ervas daninhas (Sampaio et al., 2008; Oliveira et al., 2009). Entretanto, o mesocarpo de coco por ser um material fibroso e inerte, apresenta baixo teor de nutrientes sendo necessário misturá-lo, com materiais orgânicos sólidos ou outros substratos comerciais (Costa et al., 2007; Sampaio et al., 2008) ou fornecer os nutrientes de acordo com as necessidades das espécies adicionando adubos em pré-plantio ou, principalmente, em fertirrigação (Ramos et al., 2012; Oliveira et al., 2014).

Recentemente vem se difundindo entre os pesquisadores e olericultores, $\mathrm{o}$ uso de produtos com ação de estimular o desenvolvimento radicular, aumentando a absorção de água e nutrientes pelas raízes, podendo favorecer também o equilíbrio hormonal da planta, denominados bioestimulantes (Santos \& Vieira, 2005).

Dentre os diversos produtos disponíveis no mercado nacional, destaca-se o Stimulate ${ }^{\circledR}$, principalmente devido à ação de seus componentes [ácido indolbutírico (auxina), cinetina (citocinina) e ácido giberélico (giberelina)] sobre o desenvolvimento das plantas. Estes reguladores de crescimento vegetal agem como mediadores de processos fisiológicos, potencializando o desenvolvimento vegetal, instigando o aumento da assimilação de água e nutrientes pela cultura (Vieira \& Castro, 2004).

Alguns estudos já foram desenvolvidos com bioestimulantes na produção de mudas de outras espécies, como melancia (Costa et al., 2008; Silva et al., 2014), constatando melhoria na qualidade das mudas.

Apesar da importância da qualidade do substrato na produção de mudas de qualidade bem como da ação benéfica dos bioestimulantes sobre o desenvolvimento vegetal, ainda não existem estudos sobre esses fatores em conjunto. Diante do exposto, o presente trabalho foi desenvolvido com o objetivo de avaliar o uso do bioestimulante e diferentes substratos no desenvolvimento de mu- das de maxixeiro, cv. Liso de Calcutá.

\section{MATERIAL E MÉTODOS}

O experimento foi conduzido de fevereiro a março de 2012, em casa de vegetação da UFERSA, em Mossoró-

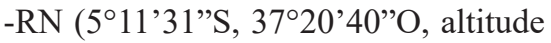
$18 \mathrm{~m})$.

A casa de vegetação utilizada tem 7 $\mathrm{m}$ de largura com $18 \mathrm{~m}$ de comprimento e estrutura de aço galvanizado. As paredes laterais e frontais são confeccionadas com tela negra (sombrite) com 50\% de sombreamento e têm cobertura em arco tipo túnel feita com filme agrícola com polietileno de baixa densidade e transparente, com $150 \mu \mathrm{m}$ de espessura e tratamento anti-ultravioleta.

Os tratamentos foram avaliados em esquema fatorial $2 \times 9$, em delineamento experimental inteiramente ao acaso, com quatro repetições, sendo a unidade experimental representada por uma população de 20 mudas. $\mathrm{O}$ fator primário das avaliações constou de duas doses do bioestimulante Stimulate ${ }^{\circledR}(0$ e $10 \mathrm{~mL} /$ $\mathrm{kg}$ de sementes) e o fator secundário por nove combinações de substratos, formulados pela mistura de fibra de coco com Tropstrato HT Hortaliças ${ }^{\circledR}$ [S1 = fibra de coco; $\mathrm{S} 2=$ fibra de coco + Tropstrato HT Hortaliças $^{\circledR}$ (4:1); S3 = fibra de coco + Tropstrato HT Hortaliças ${ }^{\circledR}$ (3:1); S4= fibra de coco + Tropstrato HT Hortaliças ${ }^{\circledR}$ (2:1); 5 = fibra de coco + Tropstrato HT Hortaliças $^{\circledR}$ (1:1); S6= fibra de coco + Tropstrato HT Hortaliças ${ }^{\circledR}$ (1:2); S7= fibra de coco + Tropstrato HT Hortaliças ${ }^{\circledR}$ (1:3); S8= fibra de coco + Tropstrato HT Hortaliças ${ }^{\circledR}$ (1:4); S9= Tropstrato HT Hortaliças $\left.{ }^{\circledR}\right]$. Após o preparo dos substratos determinou-se a capacidade de retenção de água, seguindo metodologia proposta por Martinez et al. (1991).

As sementes foram tratadas com o bioestimulante comercial Stimulate ${ }^{\circledR}$ ( $0,009 \%$ de cinetina; $0,005 \%$ de ácido giberélico; $0,005 \%$ de ácido indolbutírico e $99,981 \%$ de ingredientes inertes) (Stoller do Brasil, 2011).

Para o tratamento das sementes, o bioestimulante foi aplicado diretamente sobre as sementes, na concentração de $10 \mathrm{~mL} / \mathrm{kg}$, com auxílio de pipeta graduada; para tanto, as sementes foram acondicionadas em sacos plásticos transparentes, que logo depois foram inflados e agitados vigorosamente durante um minuto, com objetivo de uniformizar a distribuição do bioestimulante; em seguida, as sementes foram postas para secar à sombra sobre papel toalha, por uma hora. Para os tratamentos referentes à ausência de bioestimulante, as sementes passaram pelo mesmo procedimento das demais utilizando apenas água destilada.

Para a determinação da capacidade de retenção de água, amostras de cada substrato foram acondicionadas em vasos $(0,5 \mathrm{~L})$ e em seguida saturadas por capilaridade por um período de 24 horas. Depois de constatada a saturação, as amostras foram cobertas com filme plástico e colocadas suspensas até o final da drenagem. Retirou-se subamostras para determinação da massa úmida (MU) e em seguida foram postas para secar em estufa de circulação forçada de $\operatorname{ar}\left(105^{\circ} \mathrm{C}\right)$. As amostras foram retiradas da estufa para obtenção da massa seca (MS), calculando-se a umidade gravimétrica (UG) através da seguinte equação $(\mathrm{UG}(\%)=[(\mathrm{MU}-\mathrm{MS}) / \mathrm{MS}] \times 100$.

A semeadura foi realizada utilizando uma semente por célula, em bandejas de PVC, com capacidade para 200 células, e dessa fase até o final do experimento, as irrigações foram diárias com o auxílio de um regador.

As mudas foram coletadas aos 21 dias após a semeadura, analisando 10 mudas de cada tratamento, escolhendo-se aquelas mais homogêneas para serem avaliadas quanto às características: número de folhas completamente expandidas (NF), altura de plantas (ALT, utilizando-se régua graduada e medindo-se da base do substrato até a inserção da última folha), diâmetro do colo (DC, utilizando um paquímetro digital e medindo-se a altura a $0,5 \mathrm{~cm}$ da superfície do torrão), comprimento da raiz principal (CRP, medido com régua graduada, a partir da inserção da raiz na base do colo até o ápice radicular), massa seca da parte aérea (MSPA), massa seca de raiz (MSR) e massa seca total (MST). Para a obtenção da massa seca, as mudas foram separadas nas diferentes partes e postas para secar em estufa de circulação de ar forçada a $65^{\circ} \mathrm{C}$ até atingir massa constante, sendo em seguida, 
pesadas em balança de precisão $(0,01 \mathrm{~g})$.

Os dados obtidos foram submetidos à análise de variância e as médias resultantes das avaliações foram comparadas entre si aplicando-se o teste Scott-Knott ao nível de 5\% de probabilidade. Os resultados foram analisados no sistema computacional de análise de variância Sisvar 5.3 (Ferreira, 2011).

\section{RESULTADOS E DISCUSSÃO}

A avaliação da capacidade de retenção de água nos diferentes substratos mostrou que houve redução na umidade residual dos mesmos na medida em que aumentou a quantidade de Tropstrato HT Hortaliças ${ }^{\circledR}$ na formulação dos substratos, obtendo-se os seguintes valores: 86,$8 ; 81,7 ; 81,2 ; 79,0 ; 78,4 ; 72,4 ; 70,9$; 70,2 e 57,8\%, para S1, S2, S3, S4, S5, S6, S7, S8 e S9, respectivamente.

Tabela 1. Número de folhas e altura de plantas de maxixeiro em função do tratamento de sementes com $\left(10 \mathrm{~mL} / \mathrm{kg}\right.$ de sementes) ou sem bioestimulante (Stimulate $\left.{ }^{\circledR}\right)$ e diferentes substratos \{number of leaves and height of gherkin seedlings depending on the seed treatment with biostimulant Stimulate ${ }^{\circledR}(10 \mathrm{~mL} / \mathrm{kg}$ seeds $)$ and different substrates $\}$. Mossoró, UFERSA, 2014.

\begin{tabular}{|c|c|c|c|c|c|c|}
\hline \multirow{3}{*}{ Substratos } & \multicolumn{3}{|c|}{ Bioestimulante } & \multicolumn{3}{|c|}{ Bioestimulante } \\
\hline & Ausência & Presença & Média & Ausência & Presença & Média \\
\hline & \multicolumn{3}{|c|}{ Número de folhas } & \multicolumn{3}{|c|}{ Altura de planta $(\mathrm{cm})$} \\
\hline S1 & $4,70 \mathrm{Aa}$ & $4,45 \mathrm{Ac}$ & 4,58 & $8,76 \mathrm{Ab}$ & $6,38 \mathrm{Ae}$ & 7,57 \\
\hline S2 & $4,81 \mathrm{Aa}$ & $4,60 \mathrm{Ac}$ & 4,71 & $8,40 \mathrm{Ab}$ & $8,61 \mathrm{Ad}$ & 8,51 \\
\hline S3 & $4,72 \mathrm{Aa}$ & $4,85 \mathrm{Ab}$ & 4,79 & $8,02 \mathrm{Ab}$ & $7,62 \mathrm{Bd}$ & 7,82 \\
\hline S4 & $4,85 \mathrm{Ba}$ & $5,20 \mathrm{Aa}$ & 5,03 & $8,52 \mathrm{Bb}$ & $14,53 \mathrm{Aa}$ & 11,53 \\
\hline S5 & $4,42 \mathrm{Ba}$ & 4,92 Aa & 4,67 & $7,66 \mathrm{Bb}$ & $11,46 \mathrm{Ac}$ & 9,56 \\
\hline S6 & $4,65 \mathrm{Ba}$ & $5,05 \mathrm{Aa}$ & 4,85 & $11,83 \mathrm{Aa}$ & $12,91 \mathrm{Ab}$ & 12,37 \\
\hline S7 & $4,67 \mathrm{Aa}$ & $4,75 \mathrm{Ab}$ & 4,71 & $10,91 \mathrm{Aa}$ & $10,64 \mathrm{Ac}$ & 10,78 \\
\hline S8 & $4,77 \mathrm{Aa}$ & $4,74 \mathrm{Ab}$ & 4,76 & $11,78 \mathrm{Aa}$ & $10,72 \mathrm{Ac}$ & 11,25 \\
\hline S9 & $3,77 \mathrm{Bb}$ & $4,12 \mathrm{Ad}$ & 3,95 & $6,87 \mathrm{Ab}$ & $6,85 \mathrm{Ae}$ & 6,87 \\
\hline Média & 4,60 & 4,74 & & 10,19 & 10,36 & \\
\hline $\mathrm{CV}(\%)$ & \multicolumn{2}{|c|}{7,55} & & \multicolumn{2}{|c|}{10,99} & \\
\hline
\end{tabular}

*Letras iguais minúsculas nas colunas e maiúsculas nas linhas não diferem entre si pelo teste de Scott-Knott, 5\% (means followed by same uppercase letter in the column and lowercase letter in the lines do not differ, Scott-Knott test, 5\%); S1= fibra de coco (coconut fiber); S2 = fibra de coco + Tropstrato HT Hortaliças (4:1) \{coconut fiber + substrate Tropstrato HT Hortaliças (4:1)\}; S3= fibra de coco + Tropstrato HT Hortaliças (3:1) \{coconut fiber + substrate Tropstrato HT Hortaliças (3:1) $\}$; S4= fibra de coco + Tropstrato HT Hortaliças (2:1) $\{$ coconut fiber + substrate Tropstrato HT Hortaliças $(2: 1)\}$; S5 = fibra de coco + Tropstrato HT Hortaliças (1:1) \{coconut fiber + substrate Tropstrato HT Hortaliças (1:1)\}; S6 = fibra de coco + Tropstrato HT Hortaliças (1:2) \{coconut fiber + substrate Tropstrato HT Hortaliças (1:2)\}; S7= fibra de coco + Tropstrato HT Hortaliças (1:3) \{coconut fiber + substrate Tropstrato HT Hortaliças (1:3)\}; S8= fibra de coco + Tropstrato HT Hortaliças (1:4) \{coconut fiber + substrate Tropstrato HT Hortaliças (1:4)\}; S9= Tropstrato HT Hortaliças (substrate Tropstrato HT Hortaliças). nutricional da planta, o que pode ser visto no pior desempenho dos substratos $\mathrm{S} 1$ e S2, que continham maiores proporções de fibra de coco, e, consequentemente, menor disponibilidade de nutrientes. Já o desempenho negativo do substrato S9 pode ser devido à menor retenção de água do mesmo, o que possivelmente, reflete na menor disponibilidade de nutrientes para as mudas.

$\mathrm{Na}$ literatura são escassos estudos sobre o uso dos substratos utilizados no presente trabalho, no entanto, estudo desenvolvido por Souza et al. (2014), avaliando mudas de cucurbitáceas com o uso do substrato comercial Tropstrato $\mathrm{HT}^{\circledR}$ em comparação com substratos alternativos à base de esterco ovino, foi constatado que os substratos alternativos proporcionaram mudas com maior número de folhas.

A altura das plantas (ALT) também foi afetada pela interação entre os fatores estudados, assim como observado para o número de folhas. Fazendo-se o desdobramento entre os fatores, percebe-se que houve efeito significativo no uso de bioestimulante apenas nos substratos S3, S4 e S5. No S3 a aplicação de bioestimulante provocou redução na ALT; por outro lado, nos substratos S4 e S5, ocorreu efeito positivo do tratamento das sementes com o bioestimulante. É possível que estes substratos apresentaram maior equilíbrio entre a capacidade de armazenamento de água e nutrientes, proporcionadas pela fibra de coco e pelo Tropstrato HT Hortaliças ${ }^{\circledR}$, respectivamente.

Com relação ao efeito dos substratos, verifica-se que na ausência de bioestimulante, as maiores alturas foram obtidas nos substratos S6, S7 e S8, não diferindo estatisticamente entre si. Nas mudas oriundas de sementes tratadas com bioestimulante, o substrato S4 proporcionou maiores valores, seguido pelo substrato S6, enquanto os menores valores ocorreram nos substratos $\mathrm{S} 1$ e S9. O menor desenvolvimento em altura das mudas nos substratos $\mathrm{S} 1$ e S9 podem ser atribuídos à deficiência de nutrientes no S1, em virtude de conter apenas fibra de coco, e pela baixa retenção de umidade no S9, conforme apresentado anteriormente.

Em estudo desenvolvido por Silva 
et al. (2014) com mudas de melancia, utilizando doses variando de 0 a $10 \mathrm{~mL} /$ kg de sementes não observaram resposta significativa para a altura das plantas.

Não foi observado efeito significativo da interação entre os fatores bioestimulante e substratos para diâmetro do colo (DC), comprimento da raiz principal (CRP) e massa seca de parte aérea (MSPA), assim, como também não houve efeito isolado do tratamento de sementes com bioestimulante para essas variáveis (Tabela 2).

Por outro lado, o DC foi afetado significativamente pelos substratos, sendo os maiores valores obtidos nos substratos $\mathrm{S} 2, \mathrm{~S} 4, \mathrm{~S} 7$ e S8, enquanto o menor diâmetro do colo ocorreu no substrato S9. Para a variável CRP, verificaram-se os maiores valores nos substratos S5 e S6, enquanto os substratos S1 e S9 proporcionaram os menores valores (Tabela 2). Ainda, na tabela 2 é apresentado o efeito dos substratos sobre a MSPA, na qual se verifica que os substratos $\mathrm{S} 2, \mathrm{~S} 3$ e S4 proporcionaram os maiores valores, não diferindo entre si estatisticamente, enquanto o substrato S9 destacou-se dos demais por proporcionar menor MSPA.

Assim como observado para a maioria das variáveis analisadas, o uso de substrato Tropstrato HT Hortaliças ${ }^{\circledR}$ puro (S9) proporcionou menor desenvolvimento das mudas. Tal resultado ocorreu porque este substrato apesar de ter elevada concentração de nutrientes em sua formulação apresentou reduzida capacidade de armazenamento de água, o que pode indisponibilizar esses nutrientes para as plantas.

Resultados semelhantes foram obtidos por Silva et al. (2014) que não observaram efeito do tratamento de sementes de melancia com o mesmo bioestimulante, não verificaram resposta significativa para essas variáveis (DC, CRP e MSPA).

Quanto às variáveis massa seca de raiz (MSR) e massa seca total (MST), verificou-se que para ambas houve efeito significativo da interação entre os fatores. No desdobramento dos fatores para MSR, verifica-se que o tratamento de sementes com bioestimulante proporcionou maior MSR nas mudas produzidas nos substratos S4, S5 e S6, não ocorrendo diferença significativa

Tabela 2. Diâmetro do colo, comprimento de raiz principal e massa seca de parte aérea em mudas de maxixe em função do tratamento de sementes com o bioestimulante Stimulate ${ }^{\circledR}(10$ $\mathrm{mL} / \mathrm{kg}$ de sementes) e diferentes substratos \{stem diameter, main root length and aboveground part dry matter of gherkin seedlings depending on the seed treatment with biostimulant (10 $\mathrm{mL} / \mathrm{kg}$ seeds) and different substrates\}. Mossoró, UFERSA, 2014.

\begin{tabular}{lccc}
\hline Substratos & $\begin{array}{c}\text { Diâmetro do } \\
\text { colo }(\mathbf{m m})\end{array}$ & $\begin{array}{c}\text { Comprimento da } \\
\text { raiz principal }(\mathbf{c m})\end{array}$ & $\begin{array}{c}\text { seca da parte } \\
\text { aérea }(\mathbf{g})\end{array}$ \\
\hline S1 & $2,15 \mathrm{~b}$ & $7,54 \mathrm{c}$ & $0,78 \mathrm{~b}$ \\
S2 & $2,31 \mathrm{a}$ & $8,76 \mathrm{~b}$ & $0,88 \mathrm{a}$ \\
S3 & $2,22 \mathrm{~b}$ & $9,09 \mathrm{~b}$ & $0,86 \mathrm{a}$ \\
S4 & $2,32 \mathrm{a}$ & $9,32 \mathrm{~b}$ & $0,92 \mathrm{a}$ \\
S5 & $2,21 \mathrm{~b}$ & $10,08 \mathrm{a}$ & $0,79 \mathrm{~b}$ \\
S6 & $2,25 \mathrm{~b}$ & $10,21 \mathrm{a}$ & $0,78 \mathrm{~b}$ \\
S7 & $2,25 \mathrm{a}$ & $8,87 \mathrm{~b}$ & $0,77 \mathrm{~b}$ \\
S8 & $2,35 \mathrm{a}$ & $8,86 \mathrm{~b}$ & $0,87 \mathrm{~b}$ \\
S9 & $1,79 \mathrm{c}$ & $7,58 \mathrm{c}$ & $0,49 \mathrm{c}$ \\
\hline Bioestimulante & & & $0,77 \mathrm{a}$ \\
\hline Ausência & $2,21 \mathrm{a}$ & $8,81 \mathrm{a}$ & $0,08 \mathrm{a}$ \\
Presença & $2,20 \mathrm{a}$ & $9,02 \mathrm{a}$ & 10,43 \\
\hline CV $(\%)$ & 5,75 & 12,28 & $\mathrm{Scot}-\mathrm{Knot}$
\end{tabular}

*Médias seguidas pela mesma letra na coluna não diferem entre si pelo teste de Scott-Knott, $5 \%$ (means followed by the same letter in the column do not differ significantly, Scott-Knott test, 5\%); S1= fibra de coco (coconut fiber); S2= fibra de coco + Tropstrato HT Hortaliças (4:1) $\{$ coconut fiber + substrate Tropstrato HT Hortaliças $(4: 1)\}$; S3= fibra de coco + Tropstrato HT Hortaliças (3:1) \{coconut fiber + substrate Tropstrato HT Hortaliças (3:1)\}; S4= fibra de coco + Tropstrato HT Hortaliças (2:1) \{coconut fiber + substrate Tropstrato HT Hortaliças $(2: 1)\}$; S5= fibra de coco + Tropstrato HT Hortaliças (1:1) \{coconut fiber + substrate Tropstrato HT Hortaliças $(1: 1)\} ;$ S6 = fibra de coco + Tropstrato HT Hortaliças (1:2) \{coconut fiber + substrate Tropstrato HT Hortaliças $(1: 2)\} ; \mathrm{S} 7=$ fibra de coco + Tropstrato HT Hortaliças (1:3) \{coconut fiber + substrate Tropstrato HT Hortaliças (1:3)\}; S8= fibra de coco + Tropstrato HT Hortaliças (1:4) \{coconut fiber + substrate Tropstrato HT Hortaliças (1:4)\}; S9= Tropstrato HT Hortaliças (substrate Tropstrato HT Hortaliças).

nos demais substratos (Tabela 3).

Em estudo desenvolvido por Reghin et al. (2000) com mudas de mandioquinha-salsa, os autores observaram que a aplicação de bioestimulante aumentou o número e o comprimento das raízes, o que resulta, consequentemente em aumento na MSR, resultados semelhantes aos obtidos por Albuquerque et al. (2009) em mudas de alface. Estes resultados confirmam a atuação do produto como estimulador do sistema radicular, podendo resultar na maior capacidade de absorção de água e nutrientes (Vieira \& Castro, 2004). Vale ressaltar que, conforme observado no presente trabalho, a composição do substrato interfere na resposta da planta ao bioestimulante, principalmente em função da disponibilidade de água e nutrientes.

Ao analisar o efeito dos substratos de acordo com cada tratamento de sementes, verificou-se que na ausência de bioestimulante, o substrato S7 apresentou MSR superior aos demais, enquanto os menores valores ocorreram nos substratos S1, S4, S5 e S9. Para mudas oriundas de sementes tratadas com bioestimulante houve maior diferença entre os substratos, em que os substratos S6 e S7 proporcionaram o desenvolvimento de mudas com maior MSR. Já os substratos S1, S2 e S9 destacaram-se dos demais por apresentarem menores valores (Tabela 3 ).

Com relação ao acúmulo de massa seca total (MST), verificou-se que não houve efeito do uso de bioestimulante nos substratos S1, S2, S4, S7, S8 e S9. Por outro lado, nos substratos S3, S5 e S6, o tratamento de sementes com bioestimulante resultou em maior MST (Tabela 3).

Com relação ao efeito dos substratos, verifica-se que o S9 resultou em mudas com menor MST independentemente do tratamento de sementes. Nos demais substratos em que se utilizaram 
Tabela 3. Massa seca de raiz e massa seca total de mudas de maxixeiro em função do tratamento de sementes com o bioestimulante Stimulate ${ }^{\circledR}$ $(10 \mathrm{~mL} / \mathrm{kg}$ de sementes) e diferentes substratos \{root dry weight and total dry matter of gherkin seedlings depending on the seed treatment with biostimulant Stimulate ${ }^{\circledR}(10 \mathrm{~mL} / \mathrm{kg}$ seeds) and different substrates $\}$. Mossoró, UFERSA, 2014.

\begin{tabular}{|c|c|c|c|c|c|c|}
\hline \multirow{3}{*}{ Substratos } & \multicolumn{3}{|c|}{ Bioestimulante } & \multicolumn{3}{|c|}{ Bioestimulante } \\
\hline & Ausência & Presença & Média & Ausência & Presença & Média \\
\hline & \multicolumn{3}{|c|}{ Massa seca de raiz (g) } & \multicolumn{3}{|c|}{ Massa seca total (g) } \\
\hline S1 & $0,13 \mathrm{Ac}$ & $0,13 \mathrm{Ad}$ & 0,13 & $0,92 \mathrm{Ab}$ & $0,91 \mathrm{Ab}$ & 0,92 \\
\hline S2 & $0,17 \mathrm{Ab}$ & $0,16 \mathrm{Ad}$ & 0,17 & $1,07 \mathrm{Aa}$ & $0,90 \mathrm{Ab}$ & 0,99 \\
\hline S3 & $0,18 \mathrm{Ab}$ & $0,21 \mathrm{Ac}$ & 0,20 & $0,97 \mathrm{Bb}$ & $1,13 \mathrm{Aa}$ & 1,05 \\
\hline S4 & $0,14 \mathrm{Bc}$ & $0,19 \mathrm{Ac}$ & 0,17 & $1,08 \mathrm{Aa}$ & 1,09 Aa & 1,09 \\
\hline S5 & $0,16 \mathrm{Bc}$ & $0,28 \mathrm{Ab}$ & 0,22 & $1,03 \mathrm{Ba}$ & $1,12 \mathrm{Aa}$ & 1,08 \\
\hline S6 & $0,23 \mathrm{Bb}$ & $0,36 \mathrm{Aa}$ & 0,30 & $1,04 \mathrm{Ba}$ & $1,12 \mathrm{Aa}$ & 1,08 \\
\hline S7 & $0,32 \mathrm{Aa}$ & $0,33 \mathrm{Aa}$ & 0,33 & $1,12 \mathrm{Aa}$ & $1,11 \mathrm{Aa}$ & 1,12 \\
\hline S8 & $0,22 \mathrm{Ab}$ & $0,22 \mathrm{Ac}$ & 0,22 & $0,98 \mathrm{Ab}$ & $1,06 \mathrm{Aa}$ & 1,02 \\
\hline S9 & $0,14 \mathrm{Ac}$ & $0,14 \mathrm{Ad}$ & 0,14 & $0,64 \mathrm{Ac}$ & $0,67 \mathrm{Ac}$ & 0,66 \\
\hline Médias & 0,19 & 0,22 & & 0,98 & 1,01 & \\
\hline CV (\%) & \multicolumn{2}{|c|}{12,77} & & \multicolumn{2}{|c|}{8,87} & \\
\hline
\end{tabular}

*Letras iguais minúsculas nas colunas e maiúsculas nas linhas não diferem entre si pelo testes de Scott-Knott, 5\% (means followed by same uppercase letter in the column and lowercase letters in the lines do not differ, Scott-Knott test, 5\%); S1= fibra de coco (coconut fiber); S2= fibra de coco + Tropstrato HT Hortaliças (4:1) \{coconut fiber + substrate Tropstrato HT Hortaliças (4:1)\}; S3= fibra de coco + Tropstrato HT Hortaliças (3:1) \{coconut fiber + substrate Tropstrato HT Hortaliças (3:1)\}; S4= fibra de coco + Tropstrato HT Hortaliças (2:1) \{coconut fiber + substrate Tropstrato HT Hortaliças $(2: 1)\}$; S5 = fibra de coco + Tropstrato HT Hortaliças (1:1) \{coconut fiber + substrate Tropstrato HT Hortaliças (1:1)\}; S6= fibra de coco + Tropstrato HT Hortaliças (1:2) \{coconut fiber + substrate Tropstrato HT Hortaliças (1:2)\}; S7= fibra de coco + Tropstrato HT Hortaliças (1:3) \{coconut fiber + substrate Tropstrato HT Hortaliças (1:3) $\}$; S8= fibra de coco + Tropstrato HT Hortaliças (1:4) \{coconut fiber + substrate Tropstrato HT Hortaliças (1:4)\}; S9= Tropstrato HT Hortaliças (+ substrate Tropstrato HT Hortaliças).

sementes tratadas com bioestimulante os substratos S3, S4, S5, S6, S7 e S8 apresentaram valores superiores aos demais e não diferiram entre si estatisticamente (Tabela 3).

Estes resultados confirmam as observações já relatadas por outros autores em diferentes culturas (Oliveira et al., 2013; Binsfeld et al., 2014), que verificaram que a resposta da cultura ao tratamento de semente do bioestimulante é variável em função da condição ambiental, principalmente na disponibilidade de nutrientes.

Os dados do referido trabalho demonstram que o uso do bioestimulante é eficiente no tratamento de sementes, contribuindo para a produção de mudas de maxixeiro mais vigorosas. Tal resposta pode ser atribuída aos hormônios vegetais constituintes no Stimulate ${ }^{\circledR}$ (auxina, citocinina e giberelina) que atuam como mediadoras do processo fisiológicos, incrementando crescimento e desenvolvimento vegetal e estimulando a divisão celular, aumentando a absorção de água e nutrientes para as plantas (Vieira \& Castro, 2004).
Segundo Leite et al. (2003), a giberelina, que é um dos componentes deste bioestimulante também tem efeito no crescimento das plântulas. Para esses autores, quando essa substância é aplicada exogenamente em sementes, não ocorre distribuição uniforme em todas as partes da planta, apresentando menor concentração de giberelina na parte aérea das plantas, e isso talvez ocorra de uma forma que seja suficiente para aumentar o hipocótilo até certo tamanho, mas não é suficiente para afetar a altura da planta.

Conforme apresentado no presente trabalho, houve grande influência dos substratos sobre o desenvolvimento das mudas, em que, para a maioria das variáveis analisadas, os substratos contendo apenas um dos materiais (S1 e S9) apresentaram menor desempenho, enquanto os substratos contendo os dois materiais e concentrações equivalentes proporcionaram melhor desenvolvimento das mudas. Tal comportamento pode ter ocorrido pela maior disponibilidade de nutrientes nestes substratos em virtude da composição química do Tropstrato
HT Hortaliças ${ }^{\circledR}$ e da maior capacidade de armazenamento de água proporcionada pela fibra de coco.

A partir dos resultados neste trabalho, pode-se concluir que o tratamento de sementes com bioestimulante Stimulate ${ }^{\circledR}$ proporcionou melhor desenvolvimento das plantas de maxixeiro Liso de Calcutá, principalmente com os substratos S4, S5 e S6.

\section{REFERÊNCIAS}

ALBUQUERQUE, KAD; SILVA, PA; OLIVEIRA, JA; CARVALHO FILHO, JLS; BOTELHO, FJ. 2009. Desenvolvimento de mudas de alface a partir de sementes armazenadas e enriquecidas com micronutrientes e reguladores de crescimento. Bioscience Journal 25: 56-65.

ANJOS, JB; LOPES, PRC; FARIA, CMB; COSTA, ND. 2003. Preparo e conservação do solo, calagem e plantio. In: SILVA, HR; COSTA, ND (eds). Melão produção. Brasília, DF: Embrapa Informação Tecnológica. p. 3539. (Frutas do Brasil, 33).

BINSFELD, JA; BARBIERE, APP; HUTH, C; CABRERA, IC; HENNING, LMM. 2014. Uso de bioativador, bioestimulante e complexo de nutrientes em sementes de soja. Pesquisa 
Agropecuária Tropical 44: 88-94.

CARDOSO, MO; BERNI, RF; OLIVEIRA, ML; VASCONCELOS, HS. 2013. Produção de mudas de maxixe com recipiente e substrato artesanal. 6p. (Comunicado Técnico, 102).

COSTA, CA; RAMOS, SJ; SAMPAIO, RA; GUILHERME, DO; FERNANDES, LA. 2007. Fibra de coco e resíduo de algodão para substrato de mudas de tomateiro. Horticultura Brasileira 25: 387-391.

COSTA, CLL; COSTA, ZVB; COSTA JÚNIOR, CO; ANDRADE, R; SANTOS, JGR. 2008. Utilização de bioestimulante na produção de mudas de melancia. Revista Verde 3: 110-115.

FERREIRA, DF. 2011. Sisvar: a computer statistical analysis system. Ciência e Agrotecnologia 35: 1039-1042.

LEITE, VM; ROSELEM, CA; RODRIGUES, JD. 2003. Gibberellin and cytokinin effects on soybean growth. Scientia Agricola 60: 537-541.

MARTÍNEZ, PF; BURÉS, S; BLANCA, F; YUSTE, MP; VALERO, J. 1991. Experimental and theorical air/water ratios of different substrate mixtures at container capacity. Acta Horticulturae 294: 241-248.

OLIVEIRA, AB; HERNANDEZ, FFF; ASSIS JÚNIOR, RN. 2009. Absorção de nutrientes em mudas de berinjela cultivadas em pó de coco verde. Revista Caatinga 22: 139-143.

OLIVEIRA, AP; OLIVEIRA, FJV; SILVA, JA; OLIVEIRA, ANP; SANTOS, RR; SILVA, DF 2010. Parcelamento e fontes de nitrogênio para produção de maxixe. Horticultura Brasileira 28: 218-221.

OLIVEIRA, FA; MEDEIROS, JF; OLIVEIRA, MKT; SOUZA, AAT; FERREIRA, JA; SOUZA, MS. 2013. Interação entre salinidade e bioestimulante na cultura do feijão caupi. Revista Brasileira de Engenharia Agrícola e Ambiental 17: 465-471.

OLIVEIRA, FA; OLIVEIRA, MKT; MEDEIROS, JF; SILVA, OMP; PAIVA, EP; MAIA, PME. 2014. Produtividade do maxixeiro cultivado em substrato e fertirrigado com soluções nutritivas. Horticultura Brasileira 32: 464467.

RAMOS, ARP; DIAS, RCS; ARAGÃO, CA; MENDES, AMS. 2012. Mudas de melancia produzidas com substrato à base de pó de coco e soluções nutritivas. Horticultura Brasileira 30: 339-344.

REGHIN, MY; OTTO, RF; SILVA, JBC. 2000. "Stimulate Mo" e proteção com "Tecido não Tecido" no pré-enraizamento de mudas de mandioquinha-salsa. Horticultura Brasileira 18: 53-56.
SAMPAIO, RA; RAMOS, SJ; GUILHERME, DO; COSTA, CA; FERNANDES, LA. 2008. Produção de mudas de tomateiro em substratos contendo fibra de coco e pó de rocha. Horticultura Brasileira 26: 499-503.

SANTOS, CMG; VIEIRA, EL. 2005. Efeito de bioestimulante na germinação de sementes, vigor de plântulas e crescimento inicial do algodoeiro. Magistra 17: 124-130.

SILVA, MJR; BOLFARINI, ACB; RODRIGUES, LFOS; ONO, EO; RODRIGUES, JD. 2014. Formação de mudas de melancia em função de diferentes concentrações e formas de aplicação de mistura de reguladores vegetais. Scientia Plena 10: 1-9.

SOUZA, EGF; SANTANA, FMS; MARTINS, BNM; PEREIRA, DL; BARROS JÚNIOR, AP; SILVEIRA, LM. 2014. Produção de mudas de cucurbitáceas utilizando esterco ovino na composição de substratos orgânicos. RevistaAgro@mbiente On-line 8: 175-183.

STOLLER DO BRASIL. 2011. Stimulate ${ }^{\circledR}$ : informativo técnico. Cosmópolis: Stoller do Brasil. Divisão Arbore, v1. 1p.

VIEIRA, EL; CASTRO, PRC. 2004. Ação de bioestimulante na cultura da soja (Glycine max L. Merrill). Cosmópolis: Stoller do Brasil. 47p. 